\title{
PSYCHOSOCIAL PROBLEMS IN PRIMARY CARE: SOME RESULTS FROM THE DUTCH NATIONAL STUDY OF MORBIDITY AND INTERVENTIONS IN GENERAL PRACTICE
}

\author{
Peter F. M. VerhaAk and Marja A. R. Tijhuis \\ Netherlands Institute of Primary Care, P.O. Box 1568, 3500 BN Utrecht, The Netherlands
}

\begin{abstract}
According to standardized screening instruments, mental distress is a common phenomenon among many patients who visit their general practitioner. However, a number of patients who seem to be in need of mental help do not put forward such a demand for help, whereas other patients who express psychosocial problems to their GP are not considered to be in need, according to a standardized measure. In this paper, a distinction has been made between the objectified needs of the patient as expressed by a standardized assessment, and the demands of the patient, expressed by the Reason for Encounter, stated during their visit at the GP. Results of a follow-up study of two cohorts of patients have been presented: one cohort presented during a 3 month period at least one articulated demand for psychosocial help, a second cohort presented at least one somatic complaint, considered by the GP as being psychological by character, without presenting any psychosocial complaint in that period. Objective needs for mental help of patients in both cohorts were assessed by means of the General Health Questionnaire. During one year all consultations of these two cohorts were registered. The following questions have been put forward: what demands for help have been put forward by the patients, what treatment have these patients got, and what has been the course of the problems during one year of patients with different needs and demands. From the results the following conclusions may be drawn: many patients with a probable mental illness (according to their objective need) present only physical symptoms. The severity of their distress however appears to be less than that of patients with a probable mental illness who do express their psychological distress overtly. More therapeutic effort is directed at psychological symptoms than at somatic symptoms, assessed as being mainly psychosocial by character. Mental health referrals have been made almost exclusively with the former group. Within both groups, most energy is devoted to patients who are really in need, according to the General Health Questionnaire. The majority of the patients with mental health problems (be they overtly presented or not) did not present psychosocial or psychosomatic complaints anymore after a 6 month period. Recovery is higher for patients with psychological symptoms; within each group recovery is higher for patients with a low GHQ-score.
\end{abstract}

Key words - general practice, mental illness, somatization, treatment of psychological complaints

\section{INTRODUCTION}

The prevalence of mental disorders within General Practice has been thoroughly investigated over the last twenty years [1-8]. An important conclusion is that most patients with psychiatric disorders consult their general practitioner regularly but not many of them are recognized by the GP as having mental disorders. Many psychological problems remain untreated, or are treated purely as somatic disorders. If a mental disorder is treated at all, it is done by the GP himself in most cases. Only a relatively small number of them are referred to specialized care.

At first sight, one cannot but conclude that GPs are doing a poor job. They have a low rate of detection and withhold specialized treatment from those patients whose mental disorders have been recognized. Such a conclusion might be drawn too quickly, due to too schematic an approach to the problem at hand. Most of the epidemiological studies mentioned above assessed patients' clinical status by means of a standardized questionnaire or interview at a particular moment in time and compared it with GP's assessment; such an approach gives a random picture in time, neglecting the past history of doctor and patient and also neglecting possible co-morbidity. In earlier publications we have reported that many patients who were probably cases of mental illness, in clinical terms, nevertheless visited their GP with demands for help for physical problems [9]. Videotaped consultations in combination with a questionnaire, completed by the GP, showed that, although mental problems were not discussed during a particular contact, the GP was aware of such problems in the majority of cases [10].

In our opinion, screening tests provide a picture of the objectified need, irrespective of the articulated demands of the patient at that particular moment, whereas a General Practitioner assesses the reason for one particular visit (i.e. the demand) and not the general mental health status of the patient. The question remains however, as to what the implications of such a situation are for the treatment and course of this heterogeneous conglomerate of explicit and hidden mental needs, combined with physical demands. 
It has been argued, especially by general practitioners, that in many cases the mental need, which accompanies physical problems might be self-limiting. Explicitation of psychological aspects and treatment of them might be counterproductive [11]. In contradistinction, the possibility of worsening the case by not recognizing these aspects has also been put forward $[12,13]$.

In this discussion, the former arguments are mainly at the level of demand, whereas the latter point to the objectified need of the patient, regardless of the explicit requests, advanced by the patient. A combination of both points of view might be worthwhile. Consequently, a one year follow-up of patients whose problems were considered by the GP as psychological in nature, was conducted. Some of these patients were probably cases of mental illness, according to standardized measurements, and others were not. Some expressed their need explicitly as psychological complaints, others were somatizing according to the GP. The goal of this study was to describe the treatment and natural course of psychological problems in general practice, in terms of needs as well as demands.

The research questions are:

(1) What demands for help have been put forward by patients, assessed by the GP as being probably mentally ill, with or without an articulated demand for mental help and with or without a probable need for mental help?

(2) What treatment has been given by the GP to patients with various combinations of need and demand?

(3) What is the course of the complaints of these various types of patients and how is it influenced by treatment probable need and explicitation of the psychological character of the problem?

\section{METHOD}

Data was collected within the framework of the Dutch National Study of Morbidity and Intervention in General Practice, conducted by the Netherlands Institute of Primary Care (NIVEL). For this study a representative sample survey of Dutch general practices $(N=103)$ was selected and all contacts with patients were registered over a period of three months. The data included the reason for visit, diagnosis, treatment and possibly referral. Reason for visit and diagnosis were classified according to the International Classification of Primary Care (ICPC) [14]. Nine of these practiccs coopcrated in a longitudinal follow-up study. This provided us with the opportunity to select two cohorts of patients based on their illness behaviour during a three month period: one cohort of patients who presented psychosocial

*These complaints will be called 'psychosomatic' in the rest of this paper. reasons for encounter (classified within chapters Psyche or Social of the ICPC) during the 3 month registration of the National Survey and one cohort of patients who presented somatic reasons for encounter (all other chapters of the ICPC), assessed by the GP as being mainly psychosocial, ${ }^{*}$ without presenting explicit psychological or social reasons for the encounter. All contacts with the patients from those two cohorts $(N=397$ resp. 411$)$ were registered during another nine months on the same registration form as that of the National Study Registration, including reason for visit, diagnosis, treatment and referrals. In addition, all patients completed questionnaires including the General Health Questionnaire (GHQ-30) and the Biographical Problem Inventory.

The GHQ is used as a first stage screening instrument for the identification of mental disorders $[1,2,8,15,16]$. It measures the likelihood of a person being classified as a psychiatric 'case'. Given a standardized clinical interview (like for example the Prsent State Examination) as a 'golden standard', the GHQ has proved to be a specific, sensitive instrument $[1,8,17]$.

The Biographical Problem Inventory is an adaptation of the Mooney Problem Checklist [18], it is an inventory of problematic experiences (emotional, material, social). Its summation is an indication of the number of problem situations a person has recently experienced.

These questionnaires were completed directly after selection of the cohorts and again one year later, when the follow-up registration had been concluded.

Twenty-one GPs in 9 practices recorded contacts of the two cohorts during a period of one year. During the first 3 months of the National Study, each contact had to be recorded by the GP. For this purpose, a research assistant was present in the practice daily to collect and check the registration forms. After selection of the cohorts, the patients could be recognized on the GP's register. After each consultation with such a patient a registration-form was completed, indicating reason for encounter, diagnosis by the GP, treatment, diagnostics, referral and several assessments by the GP. Every two weeks a research-assistant visited the practice, and collected and checked the forms. It is reasonable to assume that during the first three months the registration covered all contacts completely. As registration was less routine during the follow-up, omissions in this period of nine month ninht be expected. A reliability study revealed that on average $83 \%$ of all contacts with the GP during the follow-up period had resulted in a completed form.

The patients in the two cohorts could not be expected to constitute a random sample. Their symptoms had been assessed at least once as being merely psychosocial in nature. Patients in cohort I (those who expressed their psychosocial complaints explicitly) were more often male and are older on average than patients in cohort II (those who presented 
Table 1. Reasons for encounter presented by patients who present explicit psychosocial problems (cohort 1) and by patients who only present somatic problems, assessed by the GP as being mainly psychosocial by nature (cohort 2). Both cohorts divided in GHQ-cases and non-GHQ-cases

\begin{tabular}{|c|c|c|c|c|c|}
\hline & \multicolumn{2}{|c|}{ Cohort 1} & \multicolumn{2}{|c|}{ Cohort 2} & \multirow{2}{*}{$\begin{array}{l}\text { Average } \\
\text { patients }\end{array}$} \\
\hline & $\mathrm{GHQ}+$ & GHQ - & $\mathrm{GHQ}+$ & GHQ - & \\
\hline $\begin{array}{l}N: \\
\text { per } 100 \text { patients } / 3 \text {-month period }\end{array}$ & 175 & 216 & 130 & 279 & \\
\hline Complaints & 371 & 322 & 254 & 267 & 208 \\
\hline Psychological complaints & 181 & 152 & - & - & 14 \\
\hline Psychosomatic complaints & 61 & 84 & 132 & 120 & 43 \\
\hline Somatic complaints & 130 & 136 & 122 & 147 & 150 \\
\hline
\end{tabular}

psychosomatic complaints). The distribution of the sexes in cohort I resembled the average distribution, in cohort II women were overrepresented. In both cohorts patients between 25 and 65 years were overrepresented. They did not differ from one another in this respect. As a consequence, married and divorced people are overrepresented in both groups and widowed and single persons are underrepresented, compared with the average practice populations.

The frequency of doctor-patient contacts in the first cohort during the 3 month selection is significantly higher than the mean number of contacts of the second cohort. Both cohorts have visited their GP more frequently than average patients. There was no difference between the two cohorts in the degree of seriousness of their complaints, as estimated by the GPs.

\section{RESULTS}

What proportion of these patients was a probable case of mental illness, according to the GHQ and what demands for help were advanced by them during the 3 months in which the patients were selected?

About $45 \%$ of the respondents who put forward explicit psychosocial complaints (cohort 1) scored above the threshold of $4 / 5$ of the GHQ-30. Thirty two percent of the patients who presented psychosomatic complaints were probable cases of mental illness according to the GHQ.

In both cohorts, patients who scored above the threshold of the GHQ had higher frequencies in all respects than patients who scored below the threshold.

From Table 1, it may also be concluded that patients with psychological complaints (cohort 1) do not only limit themselves to explicitly stated psychological complaints. Somatic and psychosomatic complaints, are presented too.

Patients from cohort 2 could, by definition, not present explicit psychosocial complaints. They present however about as many somatic complaints, which are also considered purely somatic by the GP as an average patient.

Because of the selection criteria, the figures for psychological and psychosomatic complaints in both cohorts are not comparable with the figures for average patients. Patients from both cohorts can be distinguished, however, by a high average frequency of contacts, compared with average patients. In this respect, cohort 1 also exceeds cohort 2 .

The next question to be answered concerns the treatment of the kind of problems distinguished. In Table 2 treatment of explicitly psychological complaints and somatic complaints, assessed as being mainly psychological is compared, split up by GHQ-caseness.

Complaints that are overtly presented as being psychological get more treatment than complaints which are judged by the GP as being psychological but which are presented in a somatic way. This cannot be attributed to the higher average GHQscore of the former group; patients with psychological complaints, who are below threshold on the GHQ, receive more treatment than patients with psychosomatic complaints and high GHQ-scores.

Table 2. Treatment of explicitly presented psychosocial problem and of somatizations with a psychosocial assessment by the GP, divided by GHQ-caseness

\begin{tabular}{|c|c|c|c|c|}
\hline & \multicolumn{2}{|c|}{ Explicitly psychosocial } & \multicolumn{2}{|c|}{$\begin{array}{l}\text { Somatization with psychosocial } \\
\text { assessment }\end{array}$} \\
\hline & $\mathrm{GHQ}+$ & GHQ- & GHQ+ & GHQ - \\
\hline $\begin{array}{l}N^{1}: \\
\text { Treatment }\end{array}$ & 216 & 262 & 223 & 363 \\
\hline Counseling by GP & $83 \% * *$ & $76 \% *$ & $64 \% * *$ & $53 \%$ \\
\hline Referral to mental health specialist & $14 \%$ & $11 \% *$ & $4 \%$ & $3 \%$ \\
\hline Consultation by GP of mental health specialist & $8 \%$ & $4 \%$ & - & - \\
\hline Mean duration of visit (min) & $13^{* *}$ & $11^{*}$ & 10 & 10 \\
\hline
\end{tabular}

*Difference between treatment of explicit psychosocial complaints and treatment of psychosomatic complaints is significant $(t$-tesi $P<0.05$ )

${ }^{* *}$ Difference beween treatment of GHQ + and GHQ - cases within one problem-category is significant $(t$-test $P<0.05)$

${ }^{1} N$ differs from preceding tables because patients from cohort 1 , presenting psychosomatic symptoms and patients from cohort 2 , presenting psychological symptoms have been added to the respective groups. 
Table 3. Proportion of patients that did not present any explicit or hidden psychosocial problems in the second half of the year

\begin{tabular}{lcccc}
\hline & \multicolumn{2}{c}{$\begin{array}{c}\text { Somatization with psychosocial } \\
\text { assessment }\end{array}$} & $\begin{array}{c}\text { Explicitly } \\
\text { psychosocial }\end{array}$ \\
\cline { 2 - 3 } & GHQ+ & GHQ - & GHQ+ & GHQ - \\
\hline$N:$ & 130 & 279 & 175 & 216 \\
$\begin{array}{l}\text { No psychosocial or psychosomatic } \\
\text { problem in 2nd half year }\end{array}$ & $67 \%$ & $79 \%$ & $55 \%$ & $67 \%$ \\
$\begin{array}{l}\text { At least one psychosocial or psychosomatic } \\
\text { problem in 2nd half year }\end{array}$ & $33 \%$ & $21 \%$ & $45 \%$ & $33 \%$ \\
\hline
\end{tabular}

There is one and a half times as much counselling for psychological symptoms than for psychosomatic symptoms; referrals to and consultation of mental health specialists almost always concern psychological symptoms, and the average duration of a consultation is $20 \%$ longer when purely psychological symptoms are concerned.

Within each group, patients who are to be considered as probable cases of mental illness, according to their GHQ-score, are more often treated by the GP himself, as can be concluded from the proportion of patients who get counselling by the GP and the average amount of time spent with them.

What are the consequences of differences in presentation of the-presumably-psychosocial-complaint and consequent differences in treatment?

In Table 3 the proportion of patients who continued to present psychological and psychosomatic symptoms is shown for the two cohorts, subdivided in GHQ-cases and non-GHQ cases.

Initially all patients in both cohorts presented explicit psychosocial or psychosomatic complaints. After 6 months a majority in all groups had recovered, in that sense that they no longer visited their GPs with either somatic manifestations of psychological ill-health (according to the GP) or overt presentation of psychological complaints.

However, $45 \%$ of the GHQ-cases and $33 \%$ of the non-GHQ-cases who presented psychological complaints at the time of selection, still presented complaints of a psychological origin in the second half year of the follow-up.

Of those patients who initially presented psychosomatic complaints, $33 \%$ of the GHQ-cases and $21 \%$ of the non-GHQ cases still presented psychosomatic or psychosocial complaints in the last six months.

It can be seen in Table 3 that the changes of recovery are better for non-GHQ cases than for
GHQ-cases. Actually, the odds-ratio is 1.66 in the case of psychosocial complaints, and even 1.85 in the case of psychosomatic complaints.

The conclusion that illness behaviour associated with mental problems, be they overtly manifest or hidden behind a somatic presentation, largely tends to disappear after some time would appear to be justified. As the probability of serious mental illness rises, the chances of a reduction in illness behaviour decreases.

To what degree can this decrease be attributed to interventions undertaken by the general practitioner or mental health specialists? See Table 4.

In this respect the results are disappointing. In fact, we were not able to trace any effect at all: patients with psychological complaints with whom the GP had counselling sessions or who had been referred to mental health agencies tended to show about the same rate of recovery as patients for whom this had not been done. There were no differences at all in psychosomatic complaints.

Patients who did receive counselling or a referral were also considered to be more serious cases (cf. Table 2). After controlling for GHQ-caseness, we may conclude that non-cases have benefited slightly morc from treatment of psychological complaints (the effect is above level of significance) while for the more severe cases no difference at all between treatment and non-treatment groups can be found.

\section{DISCUSSION AND CONCLUSION}

Regarding the relationship between standardized needs and the demands put forward by the patient, the following points may be mentioned.

Within a limited period, many patients with a probable mental illness, in terms of their score on the GHQ, present only physical symptoms. We should

Table 4. Proportion of patients without psychosocial respectively psychosomatic symptoms in the 2 nd half

\begin{tabular}{|c|c|c|c|c|}
\hline & \multicolumn{2}{|c|}{ Counselling } & \multicolumn{2}{|c|}{ Referral } \\
\hline & No & Yes & No & Yes \\
\hline $\begin{array}{l}\text { Psychosocial complaints: } \\
\text { GHQ+: } \\
\text { GHQ - : }\end{array}$ & $\begin{array}{l}62 \%(N=78) \\
69 \%(N=111)\end{array}$ & $\begin{array}{l}62 \%(N=138) \\
76 \%(N=151)\end{array}$ & $\begin{array}{l}62 \%(N=191) \\
72 \%(N=233)\end{array}$ & $\begin{array}{l}64 \%(N=25) \\
76 \%(N=29)\end{array}$ \\
\hline $\begin{array}{l}\text { Somatizations } \\
\text { GHQ+: } \\
\text { GHQ-: }\end{array}$ & $\begin{array}{l}73 \%(N=122) \\
79 \%(N=209)\end{array}$ & $\begin{array}{l}75 \%(N=101) \\
79 \%(N=154)\end{array}$ & $\begin{array}{l}75 \%(N=209) \\
79 \%(N=343)\end{array}$ & $\begin{array}{l}64 \%(N=14) \\
80 \%(N=20)\end{array}$ \\
\hline
\end{tabular}


keep in mind in this respect that only cases which were recognized by the GP have been taken into consideration. It is a common finding in general practice that many probable cases of mental illness only present physical complaints [8, 19].

A relatively large number of patients, who are not probable cases of mental illness, nevertheless present psychosocial or psychosomatic complaints to their general practitioner. Though an objectified need has not been established with them, their demands are such, that they surpass the somatizing patients who actually are a probable case of mental illness, in the the attention they require from their GP. Besides, patients who are known to have psychological complaints, visit their GP with purely physical symptoms too.

In summary: patients with an explicit psychological demand exceed patients with somatic reasons for encounter in degree of distress and in the actual appeal they do to their GP.

Within each group, patients with a higher objectified need present more symptoms than patients who are according to the GHQ not in need of mental help.

The result that somatizing patients in general are less psychologically distressed than patients presenting with psychological problems has been reported earlier by Bridges et al. [18] and Wright [20]. Wright also confirms our result that patients who present psychological problems visit their GP more frequently with longer consultations than patients who restrict themselves to somatic complaints.

The same conclusion may be drawn as regards treatment: more therapeutic effort is directed at psychosocial problems which are presented as such than at somatic complaints, assessed by the GP as being mainly psychosocial by character. Mental health referrals in particular have been made almost exclusively with the former group of complaints. Within each group (patients who present overtly psychosocial distress and somatizers), most energy is apparently devoted to those patients whose complaints are most serious, as measured by the GHQ. But again, objectified need comes after the subjective demand of the patient. Kessler et al. [21] concluded also that GHQ and psychiatric reason for visit were significantly correlated with receiving any mental health treatment, but attached more weight to GHQ-score.

Ormel et al. [22] conclude that psychological reasons for encounter, besides severity, recency of onset and psychiatric co-morbidity, contribute to GP's case recognition as well as mental health treatment and outcome. Earlier analysis of videotaped consultations [23] also revealed that in about $90 \%$ of the cases a psychologically statcd rcquest for hclp resulted in mental health treatment, whereas reasons for encounter, assessed by the GP as being 'physical complaints with psychosocial background' only resulted in mental health treatment in $50 \%$ of the cases.
In general more than half of the persons with mental health problems (be they overtly presented or not) do not present psychosocial or psychosomatic complaints at the end of a 6 month period. A higher proportion of the patients with initial psychosomatic complaints recover than patients with explicit psychosocial complaints. Again, within both groups, the objectified need as indicated by the GHQ introduces a second ranking.

Mann et al. [24] report about $50 \%$ recovery for a sample of 100 neurotic men and women. The only significant variable, assessed at the beginning, to affect this outcome was the overall severity of the psychiatric illness, assessed by a psychiatrist. Their worse outcome, compared with the outcome reported in Table 4 , might be due to a stricter definition of 'caseness'. The effect of severity is not contradictory to our findings: patients with psychosomatic problems tend to recover more than patients with psychological problems (the former as a whole being considered as less severe than the latter [18]) and patients with high GHQ have a poorer rate than patients with a low GHQ.

A significant finding in this respect is the lack of proof of any treatment effect, even after controlling for severity. Ormel et al. [21] who found similar results (especially regarding counselling and referral) hypothesize that the less effective GPs are in their interventions, the more mental health treatment they will provide.

In the introduction we distinguished the demand for help, representing the subjective experience of the patient, and the objectified need, as expressed by standardized instruments. We may conclude from our findings that such a need relatively often results in a request for help; such a request is a good guarantee that actual treatment will be offered. If a patient sticks to somatizations, the odds that the symptoms disappear are nevertheless higher than for psychological symptoms.

We cannot but conclude from patients' illness behaviour that a lot of patients do not put forward any demands for help at the end of a year, although a lot of them keep a high score on GHQ. However, the common sense theory that most psychological distress disappears as time goes by, cannot be considered as being corroborated. Too many patients continued to suffer from their psychological complaints. As our results do not indicate that specialists in mental health care are more successful than general practitioners, it does not seem fair to put the blame for this situation on the side of the GP. On the contrary, though general practice should do better still, it should be pointed out once more, that most energy was spent on those patients who 'objectively' needed it most. The task in specialists' hands is perhaps to keep on trying to provide general practice with better tools for those areas where yet more is to be gained. 


\section{REFERENCES}

1. Goldberg D. P. and Bridges K. Screening for psychiatric illness in general practice: the general practitioner versus the screening questionnaire. J. R. Coll. Gen. Pract. 37, (1) 15,1987

2. Goldberg D. P. and Huxley P. Mental Illness in the Community, the Pathway to Psvchiatric Care. Tavistock, London, 1980.

3. Lamberts $H$. and Hartman B. Psychische en socialc problemen in de huisartspraktijk. Huisarts en Wetenschap 25, 333, 1982.

4. Sartorius N., Goldberg D., Girlamo G. de, Costa e Silva J. A., Lecrubier Y. and Wittchen H-U. (Eds) Psychological Disorders in General Medical Settings. Hogrefe \& Huber, Toronto, 1990.

5. Shepherd M., Cooper B., Brown A. C. and Kalton G. Psychiatric Illness in General Practice, 2nd edn. Oxford University Press, Oxford, 1981.

6. Shepherd M., Wilkinson G. and Williams P. (Eds) Mental Illness in Primary Care Settings. Tavistock, London, 1986.

7. Wilkinson G. Mental Health Practices in Primary Care Settings. An Annotated Bibliography. Tavistock, London, 1985.

8. Wilnink F. M. Patient, physician, psychiatrist. Assessment of mental health problems in primary care. Dissertation State University of Groningen, 1989

9. Verhaak P. F. M., Wennink H. J. and Tijhuis M. A. R. The importance of the GHQ in gencral practice. Family. Practice 7, (4), 319, 1990.

10. Rensing I. M. and Beerendonk P. Psychosociale prohlemen in de huisartspraktijk. (Psychosocial problems in general practice). Maandhlad Geestelijke Volksgezondheid 45, (6), 595, 1990.

11. Huygen F. J. A. A family physician's concept of mental health and mental health services. In Mental Health and Primary Care (Edited by Visser G. J., Bensing J. M., Gersons B. P. R.. Maoz B. and Margolis C. Z.). Dutch and Israeli experience. NIVEL. Utrecht. 1986

12. Goldberg D. Reasons for misdiagnosis. In Psychological Disorders in General Medical Settings (Edited by Sartorius N., Goldberg D.. Girlamo G. de. Costa e Silva J. A.. Lebrubier Y. and Wittchen H-U.). Hogrefe \& IIuber, Toronto, 1990
13. Ormel J. and Giel R. Medical effects of nonrecognition of affective disorders in primary care. In Psychological Disorders in General Medical Settings (Edited by Sartorius N., Goldberg D., Girlamo G. de, Costa e Silva J. A., Lecrubier Y. and Wittchen H-U.). Hogrefe \& Huber, Toronto, 1990.

14. Lamberts $\mathrm{H}$. and Wood M. (Eds) ICPC, International Classification of Primary Care. Oxford University Press, Oxford, 1987.

15. Goldberg D. P. The Detection of Psychiatric Illness by Questionnaire. Oxford University Press, London, 1972.

16. Wright A. F. and Perini A. F. Hidden psychiatric illness: use of the General Health Questionnaire in general practice. J. R. Coll. Gen. Pract. 37, (4), 164. 1987.

17. Wilkinson M. J. B. and Barczak P. Psychiatric screening in general practice: comparison of the general health questionnaire and the hospital anxiety scale. $J . R$. Coll. Gen. Pract. 38, 311, 1988

18. Furer J. W. and Tax B. (Eds) Somatische klachten, psychiatrische symptomen en psychosociale problemen: Prevalentie, overlappingen en verbanden met demografische variabelen. Eindrapport van het Regioprojekt Nijmegen, deel 1, 1987.

19. Bridges K., Goldberg D., Evans B. and Sharpe T Determinants of somatization in primary care. Psychol. Med. 21, 473, 1991.

20. Wright A. F. A study of the presentation of somatic symptoms in general practice by patients with psychiatric disturbance. Br. J. gen. Pract. 40, (11), 459, 1990.

21. Kessler L. G., Amick B. C. and Thompson J Factors influencing the diagnosis of mental disorder among primary care patients. Med. Care 23, (1), 50 , 1985.

22. Ormel J., Brink W. vd., Koeter M., Giel R., Meer K. vd., Willige G. vd and Wilmink F. W. Recognition, management and outcome of psychological disorders in primary care: a naturalistic follow-up study. Psychol. Med. 20, 909, 1990.

23. Verhaak P. F. M. and Wennink H. J. What does a doctor do with psychosocial problems in primary care? Int. J. Psychiat. Med. 20, (2), 151, 1990.

24. Mann A. H., Jenkins R. and Belsey E. The twelve month outcome of patients with neurotic illness in general practice. Psychol. Med. 11, 535, 1981. 